\title{
Accumulation of LamB-LacZ Hybrid Proteins in Intracytoplasmic Membrane-like Structures in Escherichia coli K12
}

\author{
By WIM VOORHOUT, TOON DE KROON, JOSÉ LEUNISSEN-BIJVELT, \\ ARIE VERKLEIJ AND JAN TOMMASSEN* \\ Department of Molecular Cell Biology and Institute for Molecular Biology, \\ State University of Utrecht, Padualaan 8, Transitorium 3, 3584 CH Utrecht, The Netherlands
}

(Received 25 August 1987)

\begin{abstract}
The subcellular location of LamB-LacZ hybrid proteins in the Escherichia coli $\mathrm{K} 12$ strains pop3234 and pop3299 was investigated by immunocytochemical detection and proteaseaccessibility experiments. Induction of the synthesis of the hybrid proteins resulted in the appearance of membrane-like structures within the cytoplasm of the cells. Labelling of ultrathin cryosections of the cells with anti- $\beta$-galactosidase or anti-LamB protein serum and protein-Agold complexes revealed that the hybrid proteins were associated with these membrane-like structures or accumulated within the cytoplasm. Protease-accessibility experiments confirmed this localization. Moreover, when low quantities of hybrid proteins were produced, i.e. in uninduced pop3234 cells or in induced pop3299 cells, the hybrid proteins were accessible to trypsin from the periplasmic side of the inner membrane, leaving protected fragments with an apparent $M_{\mathrm{r}}$ of 83000 . Apparently, these hybrid proteins are partly translocated through the inner membrane, resulting in membrane-spanning forms of the proteins.
\end{abstract}

\section{INTRODUCTION}

To identify information within outer-membrane proteins of Escherichia coli required for their translocation, gene fusions have been extensively employed (Silhavy et al., 1977; Hall et al., 1982; Tommassen et al., 1985). A PhoE-LacZ hybrid protein has recently been described, encompassing a large $\mathrm{N}$-terminal portion of outer-membrane $\mathrm{PhoE}$ protein, fused to $\beta$ galactosidase (Tommassen et al., 1985). Cell fractionation experiments suggested that the hybrid protein is efficiently translocated to the outer membrane, whereas immunocytochemical labelling experiments showed that the protein accumulated in the cytoplasm. Proteaseaccessibility experiments confirmed the latter location, and, in addition, revealed that a minor amount of hybrid protein spans the inner membrane (Tommassen \& De Kroon, 1987). Expression of the hybrid protein is lethal to the cells and leads to the accumulation of precursors of exported proteins (Tommassen et al., 1985). This phenotype is consistent with the failure of cells to export the hybrid protein, rather than with efficient translocation to the outer membrane.

Gene fusions were previously employed to identify export information in another outermembrane protein, LamB. The synthesis of this protein is induced by the presence of maltose in the growth medium (Schwartz, 1967). It was shown that the encoded hybrid proteins cofractionated with the outer membrane, provided that they contained a sufficiently large $\mathrm{N}$ terminal fragment of LamB (Silhavy et al., 1977; Hall et al., 1982). Current models for the translocation of outer-membrane proteins are based on this observation (e.g. Emr et al., 1980). However, the interpretation of these results has to be questioned now that cell fractionation experiments appear to be unreliable for the subcellular localization of the PhoE-LacZ hybrid

Abbreviation: GIRA, gel immunoradioassay. 
protein. Therefore, we decided to re-investigate the subcellular localization of these LamBLacZ hybrid proteins by immunocytochemical labelling and protease-accessibility experiments. The results of these studies are presented.

\section{METHODS}

Bacterial strains and culture conditions. The $E$. coli $\mathrm{K} 12$ strains pop3234 and pop3299 have been described by Hall et al. (1982). Both strains contain a lamB-lacZ fusion gene on the chromosome and a deletion of the authentic lac $Z$ gene. The fusion genes in pop3234 and pop3299 contain approximately one-half and two-thirds of the lamB gene, respectively, fused to $l a c Z$. Upon cell fractionations, the product of the former gene was found evenly distributed among the cytoplasm, cytoplasmic membrane and outer membrane, whereas the latter gene product efficiently cofractionated with the outer membrane (Hall et al., 1982).

Cells were grown at $30^{\circ} \mathrm{C}$ in a synthetic medium (Lugtenberg et al., 1976) supplemented with $0.4 \%$ (w/v) glycerol as carbon source. To induce the synthesis of the LamB-LacZ fusion proteins, an overnight culture in this medium was diluted 1 in 25 in fresh medium. After $2.5 \mathrm{~h}$ incubation at $30^{\circ} \mathrm{C}, 0.4 \%(\mathrm{w} / \mathrm{v})$ maltose was added and incubation was continued for $5 \mathrm{~h}$.

Immunocytochemical labelling on cryosections. Immunocytochemical labelling of the hybrid proteins on ultrathin cryosections of $E$. coli cells was done as described by Tommassen et al. (1985). Ultrathin cryosections were incubated with polyclonal antiserum against $\beta$-galactosidase or LamB and subsequently incubated with proteinA-gold complexes which were prepared as described by Van Bergen en Henegouwen \& Leunissen (1986).

Protease-accessibility experiments. Cells were treated with trypsin in the presence of either $\mathrm{MgCl}_{2}$ or EDTA as described by Tommassen \& Lugtenberg (1984), except that $0.25 \mathrm{M}$-sucrose was present during trypsin treatment. The presence of EDTA allows entrance of trypsin into the periplasm.

In an alternative procedure, cells were converted to spheroplasts (Witholt et al., 1976) prior to trypsin treatment (Tommassen \& De Kroon, 1987).

$S D S-P A G E$. Cells or spheroplasts were pelleted by centrifugation for $1 \mathrm{~min}$ in an Eppendorf centrifuge, resuspended in sample buffer (Lugtenberg et al., 1975) and heated for $5 \mathrm{~min}$ at $95{ }^{\circ} \mathrm{C}$ prior to application on an SDS-PAGE gel. SDS-PAGE was done as described by Lugtenberg et al. (1975), except that the acrylamide concentration in the gels was $9 \%(\mathrm{w} / \mathrm{v})$ instead of $11 \%$. Protein bands in the gels were immunologically identified by a gel immunoradioassay (GIRA) (Poolman \& Zanen, 1980).

\section{RESULTS}

\section{Immunocytochemical localization of LamB-LacZ hybrid proteins}

When uninduced cells of strain pop3234 were sectioned and labelled with anti-LamB or anti$\beta$-galactosidase serum and protein-A-gold complexes, a few gold particles per cell were observed (Fig. $1 a, b$ ). It is not clear whether these gold particles indicate aspecific labelling or a basic level of production of hybrid protein in uninduced cells. Much more labelling was observed with both antisera in cells which were induced for the production of hybrid protein by growth for $5 \mathrm{~h}$ in the presence of maltose (Fig. $1 c, d$ ). In addition, it was observed that over $50 \%$ of the cells contained membrane-like structures within the cytoplasm (Fig. 1d). The immunogold label was found in association with these membrane-like structures and in the cytoplasm. Sometimes aggregates were observed as shown in Fig. $1(c)$.

Induction of the synthesis of LamB-LacZ fusion protein in strain pop3299 resulted in only a slight increment in the number of gold particles observed as compared with the uninduced cells. This is in agreement with the much lower levels of production of hybrid protein in this strain as compared with strain pop3234 (see below). Again, membrane-like structures were observed in the cytoplasm of the maltose-grown cells and immunogold label was observed in the cytoplasm or in association with these membrane-like structures (Fig. $1 e, f$ ). Some labelling was observed outside the cytoplasm, especially when anti-LamB protein serum was used.

\section{Protease-accessibility experiments with strain pop3234}

Total cellular proteins of cells of strain pop3234 were separated by SDS-PAGE (Fig. 2). A band with an apparent $M_{\mathrm{r}}$ as expected for the LamB-LacZ fusion protein was detected in maltose-induced cells. In addition, a weaker band with approximately the same $M_{\mathrm{r}}$ as $\beta$ galactosidase was observed in these cells, suggesting some proteolytic degradation of the hybrid 

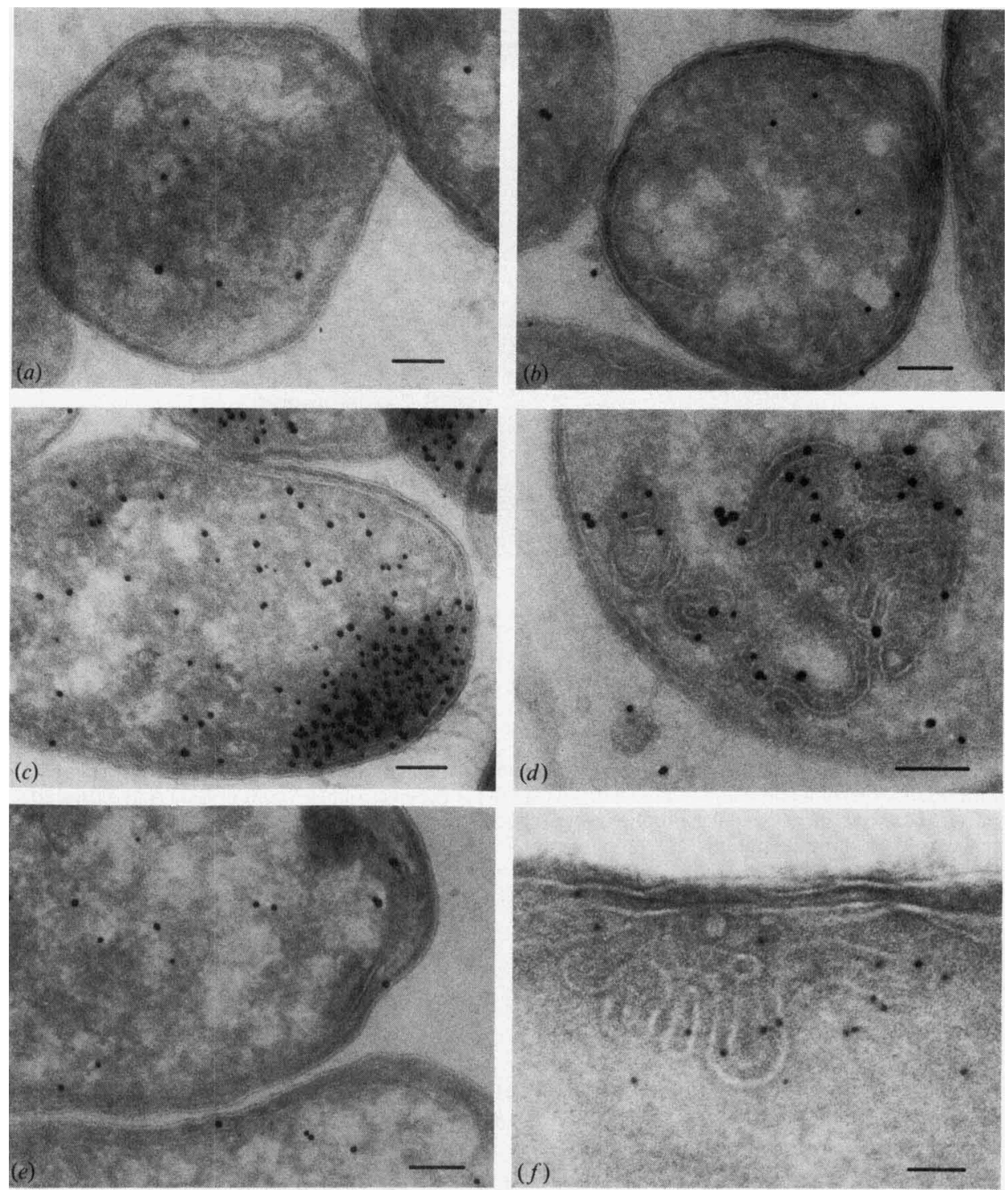

Fig. 1. Immunocytochemical localization of LamB-LacZ proteins in ultrathin cryosections. The panels show uninduced cells of strain pop3234 $(a, b)$, maltose-induced pop3234 $(c, d)$ and maltose-induced pop3299 $(e, f)$. For the labelling of the sections shown in panels $(a),(c)$ and $(e)$, anti- $\beta$-galactosidase serum was used. In $(b),(d)$ and $(f)$, anti-LamB protein serum was used. The bars represent $0 \cdot 1 \mu \mathrm{m}$.

protein by cellular proteases. The identity of these bands was confirmed by employing the GIRA technique. Both bands reacted with anti- $\beta$-galactosidase serum (Fig. 3, lane A). Only the upper band reacted with anti-LamB protein serum (result not shown).

When induced cells were treated with trypsin in the presence of $\mathrm{Mg}^{2+}$ ions, no degradation of the hybrid protein was observed. This was also the case when trypsin treatment was done in the presence of EDTA to allow entrance of the trypsin into the periplasm (Figs 2 and 3). Also, when spheroplasts were treated with trypsin, no degradation of the hybrid protein was observed, but in cell envelopes, the protein was sensitive to trypsin (results not shown). It appears that the (vast majority of) hybrid protein is not exposed at the outside surface or in the periplasm of the cells. 


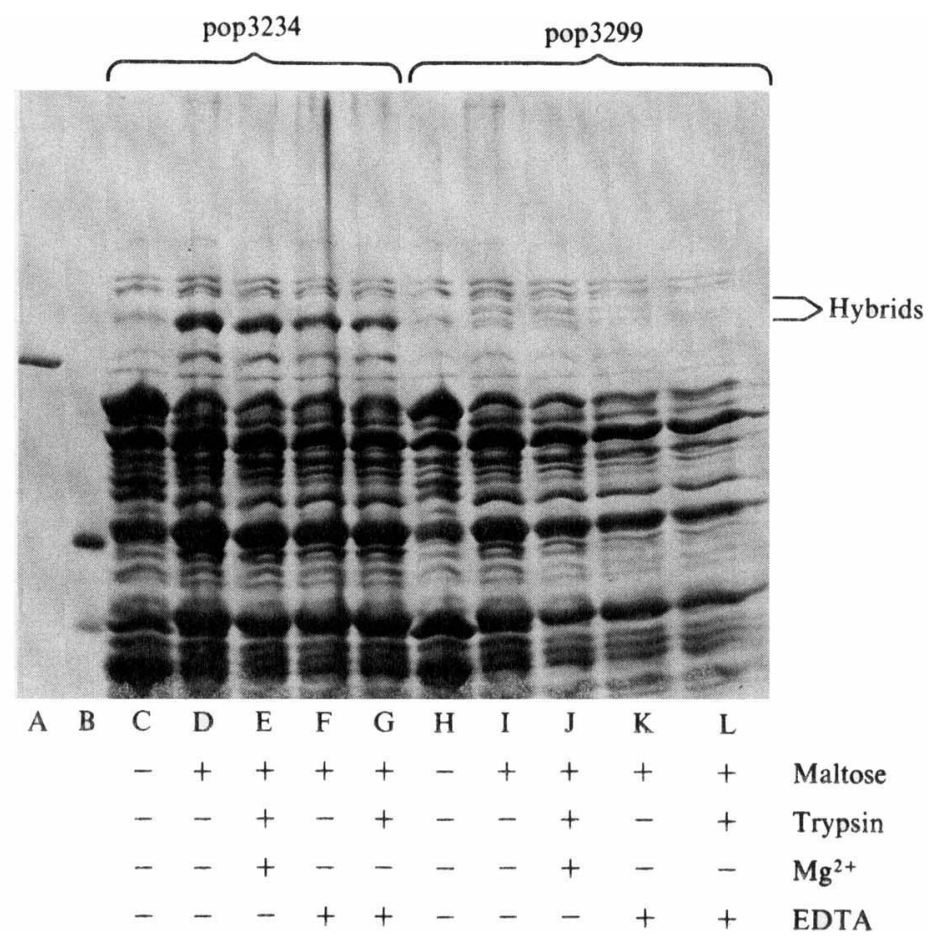

Fig. 2. Trypsin-accessibility experiments. Strains pop3234 and pop3299 were grown in the absence (-) or presence $(+)$ of maltose and treated with trypsin in the presence of $\mathbf{M g}^{2+}$ ions or EDTA as indicated. After these treatments, cellular proteins were separated by SDS-PAGE. Lane A contains purified $\beta$ galactosidase; lane B contains $M_{\mathrm{r}}$ standard proteins. Only the relevant part of the gel is shown.

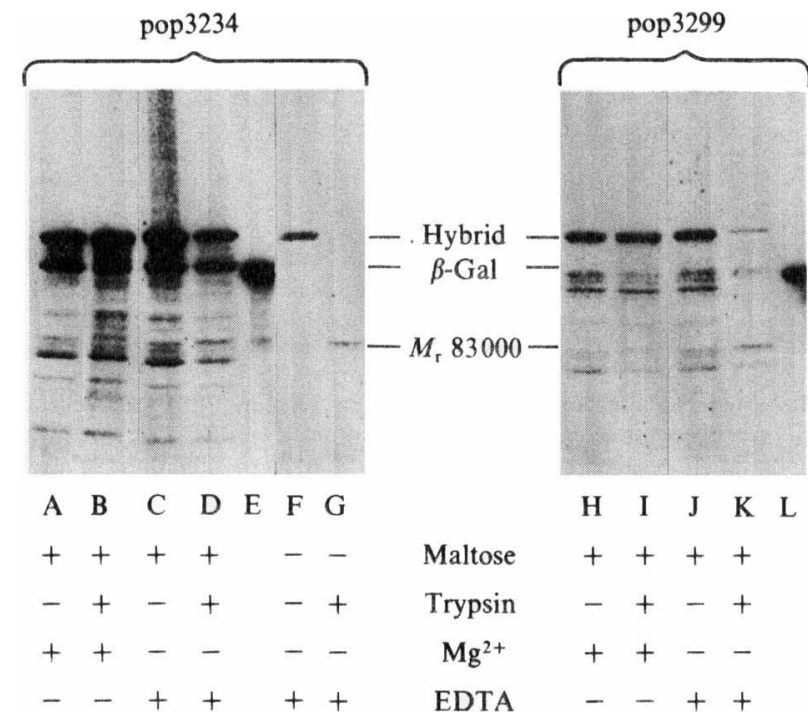

Fig. 3. Immunological identification of hybrid proteins and protein fragments in GIRA experiments. After SDS-PAGE of protein samples, the gels were sliced and gel slices were successively incubated with anti- $\beta$-galactosidase serum and ${ }^{125} \mathrm{I}$-labelled protein A. Autoradiograms of gel slices are shown. Strains pop3234 and pop3299 were grown in the presence $(+)$ or absence $(-)$ of maltose and treated with trypsin in the presence of $\mathrm{Mg}^{2+}$ ions or EDTA as indicated. Lanes $\mathrm{E}$ and $\mathrm{L}$ contain purified $\beta$ galactosidase. 
When GIRA experiments were done on total cellular proteins of uninduced cells, two bands reacting with anti- $\beta$-galactosidase serum were observed (Fig. 3, Lane $F$ ). These bands also reacted with anti-LamB protein serum (not shown) and are apparently the result of some basic level of hybrid protein synthesis in uninduced cells. These bands could well represent the precursor and the processed form of the hybrid protein. These bands were degraded during trypsin/EDTA treatment of cells, leaving a major degradation product with an apparent $M_{\mathrm{r}}$ of 83000 (Fig. 3, lane G). This degradation product reacted with anti- $\beta$-galactosidase serum, but not with anti-LamB protein serum. Therefore, this fusion protein may represent an innermembrane-spanning form of the hybrid protein of which the LamB moiety and part of the $\beta$ galactosidase moiety are accessible to trypsin in the periplasm, whereas a large part is still protected in the cytoplasm.

\section{Protease-accessibility experiments with strain pop 3299}

Growth of strain pop3299 in the presence of maltose resulted in the appearance of a double band when total cellular proteins were separated by SDS-PAGE (Fig. 2). Both bands reacted with anti- $\beta$-galactosidase serum (Fig. 3, lane $\mathrm{H}$ ) and with anti-LamB protein serum (not shown). These bands may represent the precursor and the processed form of the LamB-LacZ hybrid protein produced by this strain. The total amount of fusion protein was much lower than in the case of strain pop3234 (Fig. 2, compare lanes D and I). This difference was also observed when $\beta$-galactosidase activity of both strains was determined (results not shown) and is consistent with the weaker labelling observed in the immunocytochemical experiments.

Both forms of the hybrid protein were protected when whole cells were treated with trypsin in the presence of $\mathrm{Mg}^{2+}$ ions (Fig. 2), showing that the proteins are not exposed at the cell surface. However, upon trypsin/EDTA treatment, the lower band protein was degraded (Fig. 2). When the GIRA technique was applied, a degradation product with an apparent $M_{\mathrm{r}}$ of 83000 was observed (Fig. 3, lane K), as was the case in uninduced pop3234 cells (Fig. 3, lane G). The presumed precursor form of the hybrid protein was hardly affected by trypsin treatment.

\section{DISCUSSION}

The subcellular localization of the two LamB-LacZ hybrid proteins was investigated. Induction of the synthesis of these proteins, which is lethal to the cells (Hall et al., 1982), led to the formation of membrane-like structures in the cytoplasm. The hybrid proteins were found to be associated with these membrane-like structures and in the cytoplasm. The hybrid proteins have been reported to co-fractionate with the outer membrane (Hall et al., 1982). Since the composition of these membrane-like structures is unknown, the fractionation results may be explained by assuming that the membrane-like structures co-fractionate with the outer membrane.

It is tempting to speculate that the membrane-like structures represent enlarged export sites of the cytoplasmic membrane. Poisoning of $E$. coli cells by the induction of the synthesis of a maltose-binding protein- $\beta$-galactosidase fusion protein has been reported to lead to a tenfold induction of the synthesis of SecA protein (Oliver \& Beckwith, 1982) which is assumed to play a role in protein export (Oliver \& Beckwith, 1981). If jamming of the export machinery by the induction of such fusion proteins leads to a tenfold increase of all components of this apparatus, such enlarged export sites may be expected. On the other hand, the overproduction of innermembrane proteins has also been reported to result in the appearance of membrane-like structures in the cytoplasm (Von Meijenburg et al., 1984; Weiner et al., 1984). Possibly, the accumulation of any membrane protein in the cytoplasm may lead to the formation of these intracytoplasmic membranes, and the LamB moiety present in the hybrid proteins is sufficient to cause this effect.

Induction of the synthesis of a PhoE-LacZ hybrid protein (Tommassen et al., 1985). was also observed to lead to the formation of membrane-like structures within the cytoplasm (unpublished observation). However, in this case the structures were only observed in a few percent of the cells. Since the phoE-lacZ hybrid gene was present on a multicopy plasmid, the 
higher rate of synthesis of this hybrid protein may have been more lethal, and thus, cells may have died before large amounts of intracytoplasmic membranes were formed. On the other hand, the conditions required for induction of the hybrid gene, i.e. phosphate limitation, may interfere with extensive phospholipid synthesis.

When low levels of hybrid protein are produced, i.e. in strain pop3234 in the absence of inducer or in strain pop3299 in the presence of inducer, the proteins appear to be partly translocated. In both cases, the fusion proteins appear to be processed and the proteins are accessible to trypsin from the periplasmic side of the inner membrane. Upon trypsin treatment, a degradation product with an apparent $M_{\mathrm{r}}$ of 83000 was detected, which is apparently protected. These fusion proteins therefore may represent membrane-spanning forms where translocation was initiated at the LamB moiety but hampered within the $\beta$-galactosidase moiety. These membrane-spanning hybrid proteins may be responsible for jamming the export apparatus, resulting in the accumulation of precursors of other exported proteins (Hall et al., 1982). When similar protease-accessibility experiments were done with cells containing a $\mathrm{PhoE}-$ LacZ hybrid protein, apparent membrane-spanning forms of the protein could also be detected. However, in this case two protected fragments with apparent $M_{\mathrm{r}}$ values of 116000 and 79000 were detected (Tommassen \& De Kroon, 1987). The reason for this discrepancy is unclear at the moment.

We thank J. Leunissen for helpful advice in immunogold labelling and M. Schwartz for providing us with strains. This work was supported by the Netherlands Foundation of Chemical Research (SON) with financial aid from the Netherlands Organization for the Advancement of Pure Research (ZWO).

\section{REFERENCES}

EmR, S. D., Hall, M. N. \& Silhavy, T. J. (1980). A mechanism of protein localization: the signal hypothesis and bacteria. Journal of Cell Biology 86, 701-711.

Hall, M. N., Schwartz, M. \& Silhavy, T. J. (1982). Sequence information within the $\operatorname{lam} B$ gene is required for proper routing of the bacteriophage $\lambda$ receptor protein to the outer membrane of Escherichia coli K-12. Journal of Molecular Biology 156, 93112.

Lugtenberg, B., Meijers, J., Peters, R., Van Der HoEk, P. \& VAN ALPHEN, L. (1975). Electrophoretic resolution of the 'major outer membrane protein' of Escherichia coli $\mathrm{K} 12$ into four bands. FEBS Letters 58, 254-258.

Lugtenberg, B., Peters, R., Bernheimer, H. \& BERENDSEN, W. (1976). Influence of cultural conditions and mutations on the composition of the outer membrane proteins of Escherichia coli. Molecular and General Genetics 147, 251-262.

OLIVER, D. B. \& BECKWITH, J. (1981). Escherichia coli mutant pleiotropically defective in the export of secreted proteins. Cell 25, 765-772.

OLIVER, D. B. \&. BECKWITH, J. (1982). Regulation of a membrane component required for protein secretion in Escherichia coli. Cell 30, 311-319.

Poolman, J. T. \& Zanen, H. C. (1980). Detection of antibody activity in human sera against meningococcal cell wall antigens using a gel-immuno-radioassay (GIRA). FEMS Microbiology Letters 7, 293-296.

ScHWARTz, M. (1967). Sur l'existence chez Escherichia coli $\mathrm{K} 12$ d'une régulation commune à la biosynthèse de récepteurs du bactériophage $\lambda$ et au métabolisme du maltose. Annales de l'Institut Pasteur 113, 685704.

Silhavy, T. J., Shuman, H. A., Beckwith, J. R. \&
SCHWARTZ, M. (1977). Use of gene fusions to study outer membrane protein localization in Escherichia coli. Proceedings of the National Academy of Sciences of the United States of America 74, 5411-5415.

Tommassen, J. \& DE KRoON, T. (1987). Subcellular localization of a PhoE-LacZ fusion protein in Escherichia coli by protease accessibility experiments reveals an inner membrane spanning form of the protein. FEBS Letters 221, 226-230.

Tommassen, J. \& LugtenberG, B. (1984). Amino terminus of outer membrane PhoE protein: localization by use of a bla-phoE hybrid gene. Journal of Bacteriology 157, 327-329.

Tommassen, J., Leunissen, J., Van Damme-Jongsten, M. \& Overduin, P. (1985). Failure of Escherichia coli K-12 to transport PhoE-LacZ hybrid proteins out of the cytoplasm. EMBO Journal 4, 1041-1047.

Van Bergen en Henegouwen, P. M. P. \& Leunissen, J. L. M. (1986). Controlled growth of colloidal gold particles and implications for labelling efficiency. Histochemistry 85, 81-87.

Von MeijenburG, K., Jørgensen, B. B. \& Van DEURS, B. (1984). Physiological and morphological effects of overproduction of membrane-bound ATP synthase in Escherichia coli K-12. EMBO Journal 3, 1791-1797.

Weiner, J. H., Lemire, B. D., Elmes, M. L., Bradley, R. D. \& Scraba, D. G. (1984). Overproduction of fumarate reductase in Escherichia coli induces a novel intracellular lipid-protein organelle. Journal of Bacteriology 158, 590-596.

Witholt, B., BoEKHOUT, M., BRoCK, M., KingMa, J., Van HeErikhuizen, H. \& De LeiJ, L. (1976). An efficient and reproducible procedure for the formation of spheroplasts from variously grown Escherichia coli. Analytical Biochemistry 74, 160-170. 